\title{
STEM Education in Asia Pacific: Challenges and Development
}

\author{
Min-Hsien Lee ${ }^{1,4} \cdot$ Ching Sing Chai ${ }^{2} \cdot$ Huang-Yao Hong ${ }^{3}$
}

Published online: 21 November 2018

(C) De La Salle University 2018

\section{Introduction}

Science, Technology, Engineering, and Mathematics (STEM) education has been viewed as foundational to economic growth by many countries in the world, and has thus received continuous attention from ministries of education. The existing reviews (Brown 2012; Mizell and Brown 2016) in the United States indicate that the research in STEM is growing, with integrative STEM constituting the largest in terms of subject matter investigated. K-12 students are also the most frequently researched student group. These reviews indicate that the research conducted so far has employed an equal spread of mixed, qualitative, and quantitative research. To gain further insights into the current emphasis on STEM education, a search on the Web of Science using the search term ("science technology engineering mathematics" OR "STEM") was conducted on September 19, 2018. The search was limited to educational research. For the last 5 years (2013-2017), there are 662 published articles with an increasing trend. Within these 662 articles, we identified several important trends.

Min-Hsien Lee

leemh@ntnu.edu.tw

1 Program of Learning Sciences, National Taiwan Normal University, Taipei, Taiwan

2 Department of Curriculum and Instruction, The Chinese University of Hong Kong, Shatin, Hong Kong SAR, Hong Kong

3 Department of Education, National Chengchi University, Taipei, Taiwan

4 Institute for Research Excellence in Learning Sciences, National Taiwan Normal University, Taipei, Taiwan

\section{Current Situation in the Asian Context}

First, the U.S.-based research accounted for two-thirds (65\%) of the studies, while Asian countries (China, Korea, Malaysia, Singapore, Taiwan, etc.) accounted for only around $8.5 \%$ of the articles. Second, issues related with equity account for almost $29 \%(N=197)$ of the articles, while only around 3\% (N=19) employ "engineering design" as the pedagogical anchor. This trend is not quite parallel with Mizell and Brown's (2016) report, which is a U.S.-based one. In comparison to the myriad studies labeled as STEM-focused but in fact dealing only with a single subject (usually science learning), only those studies involving engineering design which are real-world oriented and inherently multidisciplinary deal with real STEM problems. Fortunately, engineering is increasingly becoming a focus, with the number of studies growing from only one in 2013 to eight in 2017. In the Asian context, there is only one study that employs engineering design as its pedagogical anchor (Lou et al. 2017), indicating the importance of engineering design as an emerging area of research. Third, there is an obvious gap in research pertaining to teacher preparation and professional development (Al Salami et al. 2017; Cavlazoglu and Stuessy 2017). Teachers play a significant role in equipping students with relevant STEM knowledge and shaping their choice of STEM career. Lee et al. (2015) longitudinal study employing logistic regression analyses of students' choice of a STEM career indicated that teachers' expectations of students are particularly influential. While the lack of focused study on teacher professional development to foster STEM learning warrants further investigation, the situation seems unsurprising. If it is already challenging for a teacher to master the pedagogical content knowledge 
(PCK) for a single subject, it would be even more difficult for him or her to develop PCK for interdisciplinary STEM learning. To further develop epistemic fluency (Markauskaite and Goodyear 2017) for fruitful interdisciplinary collaboration in pedagogical design work, it is asking for a special breed of teachers to design lessons that will require a substantial amount of time and effort. The three orders of barriers articulated by Tsai and Chai (2012) would need concerted effort to negotiate. In short, STEM education is a necessary and difficult challenge for today's educators to collectively pursue workable solutions.

Given the current gaps in research in STEM education, this special issue was accepted by the journal editorial committee after review, and was initially targeted to call for research papers pertaining to integrative STEM education. While we did not specifically focus on teacher education, the accepted submissions nonetheless heavily targeted STEM teacher professional development. Apparently, concerns about teachers' capacity have emerged as the top priority, and the technological pedagogical content knowledge has also emerged as a possible partial theoretical framework in STEM education.

\section{Overview of the Seven Studies}

This special issue includes seven papers, of which five particularly deal with teachers' STEM teaching, and the other two investigate students' STEM learning. The first paper, by Chai, reviewed 20 studies pertaining to teacher professional development for STEM education from the perspective of technological pedagogical content knowledge (TPACK). He proposes that underlying the TPACK framework is the notion of the teacher as a designer who creates TPACK to facilitate students' STEM learning through design thinking. STEM education necessarily requires teachers to integrate technology, pedagogy, and associated content knowledge through design. Moreover, the engineering design is emerging as the key focus, with future research needing to examine teacher-educators' and teachers' Technological Pedagogical Engineering Knowledge (TPAEK).

It is recognized that, in the area of research in STEM education, there is a lack of a validated instrument to assess teachers' self-efficacy regarding their STEM abilities or knowledge. The second paper, by Lee, Hsu, and Chang, developed a new survey to examine teachers' perceived self-efficacy in STEM knowledge. They followed Kelley and Knowles' (2016) conceptual framework for integrated STEM education (which consists of four core components including scientific inquiry, technology use, engineering design, and mathematical thinking) and also Mishra and Koehler's (2006) TPACK framework to illustrate the possible combinations of STEM knowledge. By recruiting 220 high school teachers in Taiwan, the results based on factor analyses and structural equation modeling indicated that the newly developed instrument was valid and reliable. Teachers' self-efficacy in Engineering Design and Mathematical Thinking plays a critical role in predicting their self-efficacy in Synthesized Knowledge of STEM, which predicts their attitudes toward STEM education. These findings suggest that to develop more effective teacher professional development in STEM education, teachers' understanding of concepts and processes that are applied through engineering design and mathematical thinking activities should be considered.

The third and fourth papers deal with in-service teachers' self-efficacy in STEM teaching. The third paper, by Dong, Xu, Song, Fu, Chai, and Huang, examined in-service teachers' self-efficacy in STEM teaching. They constructed a hypothesized model including teaching self-efficacy, pedagogical design self-efficacy, discipline knowledge, administration support, and collegial support, and investigated their structural effects on teacher engagement. The structural equation modeling results of 458 Chinese inservice teachers showed that teacher engagement in STEM teaching can be improved once they are more confident of their class design and teaching competencies, and if they can get enough support from peers. The findings provide insights into STEM teacher professional development. Moreover, the fourth paper, by Geng, Jong, and Chai, examined 235 in-service teachers' self-efficacy and concerns about STEM education in Hong Kong. Their study shows that almost half of the teachers are not quite ready for STEM education, and that the teachers have intense "information," "management" and "consequence" concerns about implementing STEM education in Hong Kong schools. This paper suggest that it is necessary to provide teachers with substantial professional development, pedagogical support, and curricular resources for improving STEM education in practice.

It is also important to realize the importance of preservice teachers' STEAM teaching competency. The fifth paper, by So, Ryoo, Park, and Choi, investigated the structural relationship among 238 pre-service teachers' art appreciation, attitude toward science, technology acceptance, creative convergence competency, and teaching competency regarding STEAM education in Korea. Their study revealed that, to foster creative convergence skills, it is necessary to develop pre-service teachers' positive attitudes toward art appreciation and science. Instead of using the fragmented approach (i.e., the knowledge and skills are learned separately in each STEM discipline) with strict disciplinary boundaries at teaching education institutions, the holistic and systemic approaches (i.e., linking concepts and skills through a real-world problem-solving 
transdisciplinary context) are suggested to enhance preservice teachers' STEAM teaching competency.

The last two papers examined whether the design of the learning environment and instruction facilitates STEM learning. The sixth paper, by Hong, Lin, Chen, and Chen, exemplifies how idea-centered knowledge-building pedagogy can be used as a theoretical principle to guide the design of effective technological environments for fostering productive STEM learning. This paper shows that students highly engaged in Knowledge-Building activities to foster community, work with ideas, and assume agency and groups, were able to design high-quality STEM products. The final paper, by Lin, Wang, and $\mathrm{Wu}$, implemented interdisciplinary STEM instruction by adopting modelingbased physics programming, and explored its learning effectiveness. They found that students in the STEM group benefited from the modeling-based instruction. The above two studies provide insights into the different considerations for effective learning environmental design and instructional alignment.

\section{Challenges and Further Development}

Reflectively, the papers in this special issue raise some important issues that are pertinent in the current worldwide climate of widening participation in STEM education, and increasing concerns about students' real-world problemsolving capacity and the twenty-first-century skills. We summarize the design issues raised as follows:

1. Addressing the needs of schools in designing integrative STEM units that improve or at least preserve students' examination results while concurrently fostering their creative and collaborative authentic problem-solving capacities. Needless to say, this asks for a very powerful pedagogical design.

2. Negotiating equitable subject representation where the science, mathematics, and technology teachers can accept the topic as enhancing their subject area (see also English 2017). Both mathematics and engineering components need to feature more strongly in future research.

3. Promoting technology-supported collaborative learning to prepare learners for the twenty-first-century workplaces when they are doing STEM. Current TPACK studies reveal that teachers' lesson designs may still be inclined toward didactic teaching (for example see Pringle et al. 2015).

4. Matching students' interests and capacities, which implies the design of a series of modular-based engineering challenges with adequate support for the differentiated needs of students.
5. Contextualizing STEM topics to current technological advancements that address the emerging needs of society: especially in the areas of green technology, elderly care, biomedical science, the Internet of Things, Artificial Intelligence, Big data, robotics, and unmanned automated vehicles. Explicit effort in connecting the core concepts and cutting-edge technology would help to update curricula and relate them to students' lived experiences.

6. Cultivating design-oriented problem solving with subject-specific technologies that is labeled as technological content knowledge (TCK) and which can help foster the students' disciplinary ways of knowing. While general productivity tools such as Office software and Web 2.0 technologies facilitate information processing and communication, TCK are technologies that subject-matter experts use to do their work, and thus are tools that need to be mastered by today's learners.

7. Closing each STEM unit with future design challenges to seed innovation needs. Design is future oriented, and design begets design. Articulating future design challenges will foster a life-long learning disposition among learners.

8. In addition to studies focusing on STEM teaching and learning, at the curriculum level, future studies should also look at how to redesign and transform the current subject-based curriculum framework used in most Asian countries into one that is more accommodative of STEM education.

9. At the policy level, studies are also needed to reexamine educational aims and policies in Asian countries, while comparing with policies of more progressive countries (e.g., the United States), in order to better promote more coherent and integrative STEM curricula.

In sum, these are design issues, from the microscopic (e.g., classroom) level to the macroscopic (e.g., national policy) level, which call for collective knowledge building from all sectors of educators, policy makers, and related stakeholders, and perhaps also student designers. The advancement of integrative STEM education is about pedagogically designing relevant and appropriate engineering design challenges for students to participate in design-oriented knowing.

\section{References}

Al Salami, M. K., Makela, C. J., \& de Miranda, M. A. (2017). Assessing changes in teachers' attitudes toward interdisciplinary 
STEM teaching. International Journal of Technology Design and Education, 27, 63-88.

Brown, J. (2012). The current status of STEM education. Journal of STEM Education, 13(5), 7-11.

Cavlazoglu, B., \& Stuessy, C. (2017). Changes in science teachers' conceptions and connections of STEM concepts and earthquake engineering. The Journal of Educational Research, 110(3), 239-254. https://doi.org/10.1080/00220671.2016.1273176.

English, L. D. (2017). Advancing elementary and middle school STEM education. International Journal of Science and Mathematics Education, 15, S5-S24. https://doi.org/10.1007/s10 763-9802-x.

Kelley, T. R., \& Knowles, J. G. (2016). A conceptual framework for integrated STEM education. International Journal of STEM Education, 3(1), 11. https://doi.org/10.1186/s40594-016-0046-z.

Lee, S. W., Min, S., \& Mamerow, G. P. (2015). Pygmalion in the classroom and the home: Expectations' role in the pipeline to STEMM. Teachers College Record, 117(9), 1-40.

Lou, S.-J., Chou, Y.-C., Shih, R.-C., \& Chung, C.-C. (2017). A study of creativity in $\mathrm{CaC}_{2}$ steamship-derived STEM project-based learning. Eurasia Journal of Mathematics Science and Technology Education, 13(6), 2387-2404.

Markauskaite, L., \& Goodyear, P. (2017). Epistemic fluency and professional education: Innovation, knowledgeable action and actionable knowledge. Dordrecht: Springer.

Mishra, P., \& Koehler, M. J. (2006). Technological pedagogical content knowledge: A framework for teacher knowledge. Teachers College Record, 108(6), 1017-1054.

Mizell, S., \& Brown, S. (2016). The current status of STEM education research 2013-2015. Journal of STEM Education, 17(4), 52-56.

Pringle, R. M., Dawson, K., \& Ritzhaupt, A. D. (2015). Integrating science and technology: Using technological pedagogical content knowledge as a framework to study the practices of science teachers. Journal of Science Education and Technology, 24(5), 648-662.

Tsai, C.-C. \& Chai, C. S. (2012). The "third"-order barrier for technology-integration instruction: Implications for teacher education. In C. P. Lim \& C. S. Chai (Eds.), Building the ICT capacity of the next generation of teachers in Asia. Australasian Journal of Educational Technology, 28 (Special issue, 6) (pp. 1057-1060). http://www.ascilite.org.au/ajet/ajet28/tsai-cc.html 